\title{
El lugar del niño y la niña en la toma de decisiones en la dinámica de aula: Reflexiones desde la pedagogía de la autonomía de Paulo Freire
}

\section{Children's Role in Classroom Decision-Making Dynamics: Reflections from Paulo Freire's Pedagogy of Freedom}

\author{
Erika Víquez-Zavala? \\ Centro Educativo Bilingüe Nuestra Señora de Lourdes \\ Heredia, Costa Rica \\ erviza84@gmail.com
}

\begin{abstract}
Recibido 3 de noviembre de 2013 • Corregido 6 de octubre de 2014 • Aceptado 31 de octubre de 2014
Resumen. Este artículo presenta tres experiencias pedagógicas desarrolladas en un aula de preescolar, que forman parte de una investigación-acción. Las experiencias son acompañadas con tres saberes que expone la pedagogía de la autonomía de Paulo Freire: una escucha totalizadora, respeto a la autonomía y un adecuado vínculo afectivo. Pretendo mostrar cómo niños y niñas de 3 a 4 años de edad, de un grupo de interactivo I del sector privado de la educación costarricense, pueden asumir un papel protagónico en la toma de decisiones en el aula. Metodológicamente, el video es la única técnica que utilicé para registrar las escenas de la dinámica de aula y sistematizar los eventos. Como reflexiones finales expongo que los niños y las niñas preescolares están en la capacidad de protagonizar un rol reflexivo, crítico y transformador, que exige respeto a su escucha, autonomía y liberación del ser.
\end{abstract}

Palabras claves. Investigación-acción, reflexión, protagonismo, transformación, autonomía, libertad.

Abstract. This paper presents three educational experiences in a preschool classroom as part of an action research project. These experiences are accompanied by three types of knowledge discussed in the Pedagogy of Freedom proposed by Paulo Freire: fully listening, respect for autonomy, and adequate emotional bond. I intend to demonstrate how 3 and 4 year-old children in a pre-kinder class (Interactive I) from a Costa Rican private school can take a leading role in the classroom decision-making process. Methodologically, video is the only technique I used to record the scenes of classroom dynamics and systematize events. As part of the final reflections, I state that preschool children are capable of taking a leading reflective, critical and transformative role that demands respect for their listening, independence and liberation of the self.

Keywords. Action research, reflection, leadership, transformation, autonomy, freedom.

\footnotetext{
${ }^{1}$ Licenciada en Pedagogía con énfasis en Educación Preescolar (UNA). Experiencia docente en instituciones educativas privadas costarricenses. Actualmente trabaja en el Centro Educativo Bilingüe Nuestra Señora de Lourdes, en Barva de Heredia, donde tiene a cargo el grupo de Interactivo I. Es estudiante de la Maestría Profesional en Pedagogía con Énfasis en Desarrollo y Atención Integral de la Primera Infancia de la Universidad Nacional Autónoma de Costa Rica.
} 
doi: http://dx.doi.org/10.15359/ree.19-1.8

URL: http://www.una.ac.cr/educare

CORREO: educare@una.cr

Cuando hablamos de investigación emerge una herencia de muchos años, donde asumíamos el supuesto de que"existe un sujeto que investiga y un objeto que es estudiado". A lo largo de la historia esta concepción ha evolucionado, se transforma para asumir un lugar interactivo de construcción, más aún cuando se trata de investigación cualitativa. Entonces, me aventuro a iniciar un proceso de investigación acción, el cual apuesta por una transformación de los procesos educativos (Latorre, 2003). Debo destacar que este artículo no contempla la totalidad de la investigación, es una muestra de tres experiencias pedagógicas, las cuales me permitieron reflexionar acerca de la importancia de brindar a los niños y las niñas un lugar desde la autonomía y la toma de decisiones.

Lo anterior surge en el marco de la "Maestría en Pedagogía con énfasis en Desarrollo y Atención Integral de la Primera Infancia"; elijo hacer investigación acción, enfocándome en el reto de hacer una introspección de mi práctica pedagógica, sistematizando mi quehacer desde algunas experiencias pedagógicas con los párvulos, tratando de explicar si mis intervenciones están en armonía con las necesidades e intereses de los niños y las niñas. Por consiguiente, inicio un análisis crítico para detallar si mi discurso es coherente en la práctica. Este proceso empieza a desdibujar muchas concepciones construidas en el cotidiano educativo e, incluso, situaciones que pasan desapercibidas en las experiencias de aula.

Desarrollo una conciencia diferente acerca de mi quehacer docente, donde emergen los verdaderos protagonistas: los niños y las niñas. De manera que afloran multiplicidad de escenarios cotidianos que cuestiono y reflexiono desde otra mirada, acompañada de los saberes que plantea Freire (2006) en la Pedagogía de la autonomía.

Esta pedagogía nos habla, específicamente en cuanto al rol docente, que debemos tener claridad en nuestra práctica pedagógica, de manera que logremos transformar la realidad para intervenir en ella y darle un nuevo sentido. Hace hincapié en que "enseñar no es transferir conocimiento, sino crear las posibilidades de su producción o de su construcción (Freire, 2006, p. 24). En este sentido, puedo argumentar que al asumir esta posición, docente y estudiantes podemos construir una dinámica de aula respetuosa de la autonomía, toma de decisiones y libertad.

En cuanto al niño y la niña se menciona que son arquitectos "de su propia práctica cognoscitiva" (Freire, 2006, p. 119). Son seres epistemológicamente curiosos, para ello es necesario que en conjunto movilicemos el pensamiento y los llevemos a la curiosidad, búsqueda y expresión; todo esto nos permitirá ir tomando decisiones en el camino, para la construcción de su autonomía.

\section{Interacciones sistémicas, realidades múltiples, procesos de vida}

El espacio pedagógico donde desarrollo la investigación acción es en un aula de preescolar, en el área de la educación privada, específicamente un grupo del nivel de interactivo l, donde asisten niños y niñas de 3 años y 3 meses a 4 años y 3 meses. Soy la docente a cargo del grupo. No obstante, recordemos que para efectos de este artículo me enfocaré únicamente en tres 
experiencias pedagógicas, las cuales me permiten hacer un análisis reflexivo de la dinámica de aula, las relaciones, las palabras, los gestos de todas las personas que interactuamos en este espacio educativo, encontrando en los saberes de Freire (2006) un camino para mejorar mi posicionamiento como docente y ofrecer a los párvulos un espacio para la toma de sus propias decisiones.

El sendero para lograr lo antes mencionado tiene su génesis en una ruptura epistemológica del modelo tradicional, que nos indica cómo el docente es el que enseña y el estudiante es un receptor de la información, con relaciones docente-estudiante verticales. Mi reto inicia cuando me replanteo la forma en que percibo a mis estudiantes, desde su potencial, con capacidad de actuar, hablar, escuchar, discrepar, reflexionar (Freire, 2006). Existimos en interconexión con todo lo que nos rodea y, por lo tanto, influimos, cambiamos, construimos, e interpretamos las diversas realidades; pero siempre manteniendo nuestra singularidad, lo que Maturana (2002) reconoce como la organización autopoiética, donde cada ser vivo se encuentra en constante transformación, al tiempo que conserva su identidad.

Ontológicamente hablando, la realidad se presenta como diversa, construida por el conjunto de seres que comparten un mismo espacio, tiempo e historia. Es una realidad cambiante, holística, en constante movimiento (Gurdián-Fernández, 2007). Las fuerzas de los seres que intercambiamos nuestras experiencias se ven fortalecidas en el devenir con los otros y las otras, así nuestra convivencia se torna más armoniosa. Lo que presentaré en las siguientes páginas son procesos de vida complejos, una forma de comprender lo incierto es hacerlo a través de la resonancia de historias, pensares, haceres, sentires, de niños, niñas y una maestra.

Empiezo el recorrido, muchos caminos se abren paso frente a mis ojos; empiezo a aventurarme en esta nueva mirada de la realidad, y con cada movimiento emergen nuevos pasajes, que están matizados por falsas imágenes o ideas preconcebidas que empiezan a desmoronarse. No sabemos lo que nos espera, pero una vez que nos adentramos en este proceso, todo puede pasar (Gurdián-Fernández, 2007).

Desde el paradigma cualitativo, me propongo asumir el reto de dar el protagonismo a párvulos de 3 y 4 años de edad, desde su realidad en la dinámica de aula. Como seres activos, con voz propia que puede ser escuchada, pensantes y críticos de su propio accionar, creativos y originales en su hacer, capaces de transformarse y transformar la realidad.

Ahora bien, en este caminar de la mano con la investigación acción, me hago acompañar de otras herramientas para la interpretación de los datos registrados durante el proceso. Como docente investigadora deberé profundizar mi mirada, que observará mi propio desempeño, esto lo lograré utilizando como técnica fundamental el video. Este instrumento de registro, según McKernan (1999), permite revelar "cualidades que pueden iluminar el conocimiento y la comprensión de la persona con respecto a la labor docente y la práctica profesional" (p. 127). 
doi: http://dx.doi.org/10.15359/ree.19-1.8

URL: http://www.una.ac.cr/educare

CORREO: educare@una.cr

La sistematización propia de la investigación acción la hago acompañar de este mecanismo de análisis-reflexión, que recopila las vivencias tal como sucedieron, permitiéndome revisar poco a poco mi cosmovisión de la realidad de aula; además me permite dimensionar la multiplicidad de historias de los protagonistas y las protagonistas que se conjugan en un tiempo y espacio determinados (Gurdián-Fernández, 2007). El video se torna una herramienta de construcción pedagógica, devela el sistema de historias de vida, pensares, sentires y haceres que constituyen la dinámica de aula; permite reflexionar y acercamos a la práctica de la libertad en el escenario educativo.

\section{Sonata en tres tiempos}

Es necesario contextualizar de donde surgen las tres experiencias que dan cuerpo al presente artículo, son momentos sistematizados de una investigación acción, las cuales me permitieron analizar mi dinámica de aula para comprender las fuerzas que me mueven a comportarme de la manera en que lo hago, a comprobar si lo que pienso, siento y aplico como docente está en armonía. De este estudio surgen nodos conceptuales, uno de ellos la importancia de la autonomía y la toma de decisiones en los niños preescolares, quienes clarifican y permiten la transformación pedagógica de mi quehacer docente.

En cada ciclo de acción-reflexión característicos de este tipo de investigación, las vivencias con los niños y las niñas me llevan a cuestionarme constantemente y buscar estrategias para compartir con ellos un verdadero rol reflexivo, crítico y transformador. Por ello, incorporo tres saberes de Freire (2006), ya que me permiten sustentar la forma en que una docente puede desarrollar su dinámica de aula desde una visión pedagogía crítica y desde el nivel de preescolar.

A continuación describiré tres experiencias pedagógicas -escenas-, que me permitieron incorporar al niño y la niña en un verdadero rol protagónico, construido desde su autonomía y toma de decisiones. Utilizo el video como técnica para la sistematización de los eventos, lo cual me permite mirar desde afuera lo sucedido, observar lo actuado, reflexionar lo sucedido, encontrar respuestas y encaminar la transformación en las posteriores escenas, todos siendo partícipes activos, tal como se espera en una investigación acción.

Para la primera escena elegí un material que nunca había utilizado con mis estudiantes, una bolsa grande con papel triturado. Mi intención era generar un espacio totalmente abierto al diálogo, ya que una posición dialógica es una premisa que ofrece una apertura hacia una mente crítica y a la participación real del ser.

Freire (2005) explica que "quien dialoga, lo hace con alguien y sobre algo" (p. 105). Esta perspectiva cambia el sentido epistemológico del proceso, los sujetos no son vistos como objetos, sino como sujetos activos en su realidad. Los estudiantes y las estudiantes tienen la oportunidad de participar en situaciones que conlleven el poder de decidir y la responsabilidad de asumir una experiencia pedagógica respetuosas de la libertad (Freire, 2006). 
Lanzo una pregunta abierta: ¿Qué parece estejuguete?, ¿qué será este juguete? (refiriéndome al papel). Inmediatamente la voz de las personas participantes se hace presente (protejo la identidad de los protagonistas y las protagonistas utilizando para su identificación una o dos letras):

Docente: ¿qué parece este juguete?

V: Ah ya sé, para tirarlo todo para arriba y que nos quede todo blanco.

Docente: ¿Es para tirarlo para arriba?

(niños y niñas responden)

B: Papel y parece nieve.

T: Para tirarlo y que quede blanca la cabeza.

D: Es una bola.

L: Para tirarlo en la cabeza y quede blanco.

Ma: Una bola toda grandota, para que la tiremos arriba y para que nos queden blancas las piernas.

Vy: Para tirarlo y que nos quede todo el cuerpo blanco.

MA: Ya sé, lo tiramos al piso y hacemos así (mueve sus manos de un lado a otro).

V: O hacemos muñecos de nieve.

MCH: Para tirarlo.

La forma en que las personas protagonistas son escuchadas refiere al primer saber que abordaré de la mano de Freire (2006). Este hace hincapié en la imperiosa necesidad de que el educador o la educadora vea a cada estudiante "como sujeto de la escucha de su habla crítica y no como objeto de su discurso" (p. 109). En el momento que como docente asumo una postura más acertada de la realidad y me involucro con mis estudiantes en la toma de decisiones, ellos y ellas se apoderan de la actividad, todos podemos expresar nuestro sentir.

Como docente reafirmo sus ideas y les pregunto: ¿Les gustaría que agarremos el papel para tirarlo? Su respuesta no se hace esperar, e inmediatamente reaccionan con su cuerpo antes que con su palabra, se acercan entre risas y algarabía a tomar partes del papel y lanzarlo cual Iluvia. Entonces me doy cuenta de que las palabras son sustituidas por el cuerpo, el niño y la niña empiezan a constituirse en ser-sujetos, se extingue esa idea errónea que solo con las palabras se obtiene el conocimiento. Asumo que somos seres corporales, el mundo simbólico de estos párvulos es visto desde una nueva dimensión sensorial, todo el cuerpo se expresa y con esto también es posible teorizar (Assmann, 2002). 
doi: http://dx.doi.org/10.15359/ree.19-1.8

URL: http://www.una.ac.cr/educare

CORREO: educare@una.cr

Avanza la experiencia, mis estudiantes dan la pauta, por lo que intervengo nuevamente con una pregunta, siempre a la vanguardia, la incertidumbre. Vamos a pensar en algo más divertido todavía: ¿Qué más podemos hacer con este papel?

MCH: Tirarse, tirarse ahí.

Docente: ¿Y si nos golpeamos?

MCH: No, suavecito.

Docente: Vamos a probar

Niños y niñas: Yo, yo, yo (la mayoría de niños y niñas se ofrecen a participar).

Esa respuesta "tirarse ahí", representa este encuentro dialógico del habla y la escucha. Es un cesar del silencio y un renacer de la indagación, la duda, la creación (Freire, 2006). Por ello es que afirmo cómo niños, niñas y docente nos escuchamos en un sentido más profundo de comprensión, nuestra convivencia despierta al son de la escucha respetuosa del otro y la otra.

El análisis de los diversos eventos trasciende, mis estudiantes son sujetos activos, el proceso les "catapulta hacia un ser subjetivo, un ser persona, que sólo se comprende en el estar o vivir con o al lado de las otras personas" (Gurdián-Fernández, 2007, p. 109). Este compartir con el otro ser desde el respeto, enriquece las experiencias pedagógicas; y también me reta a mí como docente, me invita a provocar curiosidad, a disfrutarla y compartirla, para no caer en la transmisión de conocimientos.

El estudiantado toma la decisión de utilizar la montaña de papel para tirarse sobre ella. Surge una dinámica diferente, asumen el espacio como propio y asignan sus propias reglas en un ambiente de libertad; como docente comparto mis ideas, no las impongo, lo hago con gusto, consiente e intencionada. En esta intervención uno de los estudiantes da la pauta a seguir:

Docente: Empecemos con $\boldsymbol{B}$.

Docente: ¿Qué vas a hacer?

B: No responde verbalmente, lo hace con su gestualidad, sobre su mano y con dos dedos hace movimientos de saltos.

Docente: Hágalo.

B: Salta sobre el papel.

Niños y niñas: (risas yo quiero, yo quiero).

B: Uno por uno (refiriéndose a tomar turnos para participar de la actividad).

Docente: Qué les parece esa idea.

Niños y niñas: Si. 
Esta propuesta no solo demuestra el nivel de intercambios generada entre los seres que compartimos ese sistema de aula, evidencia la autonomía y creatividad que pueden ejercer párvulos de 3 y 4 años de edad. La voz de cada protagonista es escuchada y el quehacer pedagógico se transforma en una herramienta de liberación. Asumimos límites en un grupo con identidad; con esto me refiero a que las individualidades son validadas, todas las personas presentes somos capaces de interactuar en armonía, hacemos de la convivencia grupal una experiencia respetuosa del otro, de sus derechos.

Los ejemplos mencionados anteriormente me permitieron determinar que esta población es capaz de tomar decisiones, dar a conocer su voz y, por ende, el grupo como tal es participe de una nueva dinámica de relaciones positivas. A su vez me posiciona en otra dimensión, nos vinculamos con respeto, alegría, libertad e incipientemente desde un lugar de intercambios horizontales.

Nos vamos transformando en el camino, retomo al sujeto en un movimiento paradigmático epistémico que me lleva nuevamente a las relaciones sistémicas y su injerencia en el diálogo, la de-construcción y re-construcción de los discursos me permiten ser activa y creadora en esta realidad cambiante (Gurdián-Fernández, 2007). Niños y niñas me recuerdan que palabra, cuerpo y emoción se articulan en el vivir cotidiano; somos actuantes del proceso investigativo y tomamos el control de nuestras propias vidas de una forma individual y colectiva. Luego de un juego lleno de movimiento, risas e interacciones, una niña argumenta:

\section{F: ¡Ahora sigue la Niña!}

Docente: ¿Sigo yo?

\section{Niños y niñas: Si.}

Docente: bueno 1, 2, 3 (la docente igual que los párvulos se tira encima del papel).

Todos: (risas).

Ella se refiere a mí como docente, ya que en nuestra cotidianeidad me llaman "niña", esto es un clamor a la reflexión, porque durante mucho tiempo que hemos compartido, es la primera vez que me hacen partícipe de una acción donde me consideran una más del grupo. Existe toda una transformación en el pensar, el sentir y el actuar; el protagonismo de los niños y las niñas trastoca todo un sistema de relaciones y también modifica mis concepciones construidas a lo largo de los años, ejemplo de ello es cuando en la dinámica de aula, hablo antes de escuchar, transmito información de una manera vertical, no percibo con claridad lo que los estudiantes desean, mi presencia limita la expresión de los demás.

Acciones como las que menciono en las líneas anteriores han pasado desapercibidas, y solamente con este tipo de estudio donde hago un ejercicio por encontrar mis debilidades y fortalecerlas de la mano con la pedagogía de la autonomía de Paulo Freire, puedo dar sentido y 
doi: http://dx.doi.org/10.15359/ree.19-1.8

URL: http://www.una.ac.cr/educare

CORREO: educare@una.cr

ejercer un cambio en el área pedagógica, donde los beneficiados son los niños y niñas que me ayudan a vislumbrar cómo es posible un quehacer docente diferente, que les de su lugar desde el rol protagónico y enciendan a su vez la inquietud por expresarse libremente, con derechos y con la capacidad de discrepar o estar de acuerdo con las vivencias que se desarrollan en el aula preescolar: esto me ha transformado en lo más profundo de mi ser.

En cuanto a mis cambios, me refiero a las relaciones de poder; sin darme cuenta estaba ejerciendo una posición vertical en la dinámica de aula, estos párvulos alcanzan un nivel de empatía propio de la investigación cualitativa, la cual me libera de ser una educadora que enseña, y resurjo en una educadora que aprende de los intercambios con sus estudiantes. Estoy en "aprendiencia":

Situación de estar-en-proceso-de-aprender, esta función del acto de aprender que construye y se construye, y su estatuto de acto existencial que caracteriza efectivamente el acto de aprender, indisociable de la dinámica de lo vivo (Trocmé-Fabre, 1997 citado por Assmann, 2002, p. 124).

Luego de varias acciones propuestas por los protagonistas y las protagonistas, hay un momento en el juego donde deciden ocultarse debajo del papel; nuevamente incluyen mi participación en su alegría, me contagian de su emoción. Una niña dice:

MCH: la niña, a la niña.

Docente: ¿Me tapan a mí?

Niños y niñas: Si.

Docente: Pueden tapar a la niña.

Niños y niñas: Toman el papel y se lo colocan encima a la docente.

Docente: Listo, isorpresa!

Todos: Risas.

Toman el papel y me lo colocan encima, acto seguido de risas, disfrute, acompañamiento y vínculo, en un espacio de camaradería. Cuando cuestiono al estudiantado participante: ¿pueden tapar a la niña (docente) con papel?, su reacción está libre de temor y llena de alegría, no hay silencio marcado por la duda. Respuesta afirmativa inmediata, con seguridad, validados como personas que pueden tomar decisiones en un ambiente de respeto.

Este nuevo escenario nace de la comprensión de que, como seres integrales que somos, validamos las acciones no solo a través de la palabra, también es posible validar a la persona desde la integralidad de los procesos, desde su gestualidad. Compartimos un espacio de respeto mutuo donde nos afianzamos como un grupo con identidad. Al finalizar este análisis de 
la primera escena, encuentro interrogantes que redireccionan la acción y la reflexión, la mirada cambia, la presencia se fortalece, mis estudiantes "se transforman en sujetos actuantes en el proceso investigativo" (Gurdián-Fernández, 2007, p. 110).

Me pregunto: ¿Cómo vivenciar la autonomía del ser desde la práctica pedagógica? ¿Qué mirada tienen los párvulos de esta realidad que se transforma en el cotidiano? Considero que el panorama anterior me genera un nivel más profundo de participación, en el caminar descubriré las nuevas rutas a seguir, continúa el proceso de análisis retomando la espiral recursiva, que me permite observar la multiplicidad de realidades, devolverme en el espacio-tiempo del video, analizar, reflexionar y nuevamente accionar (Latorre, 2003). En este vórtice de preguntas y ansiedad cognoscitiva, emerge la segunda experiencia pedagógica, la cual se desarrolla con la misma intención de incursionar en nuevas oportunidades que permitan fortalecer procesos creadores, autónomos y liberadores.

Para esta escena, la tónica es desestructurarnos, comprendernos desde el respeto, participar de las vivencias con plena seguridad de que la voz del estudiantado será respetada en todos sus sentidos. Para este momento de acción utilizamos almohadas. Pretendo mostrar cómo me acompaña un nuevo saber de Paulo Freire, en este caso el que hace referencia a la existencia de un profundo "respeto a la autonomía del ser del educando" (Freire, 2006, p. 58).

La actividad inicia con mucha emoción, niños y niñas están inquietos, deseosos de ver qué sucederá con las almohadas. No puedo imaginar todas las ideas que pueden confabularse en sus mentes, lo que sí puedo hacer es brindar el espacio para que eso que no es posible poner en palabras, sea expresado con sus cuerpos.

Entonces mis palabras pueden ser una extensión del pensar de los párvulos, debo tener muy claro mi lugar en este instante, mis intenciones no pueden limitar la acción. Mi expresividad es diferente cuando hago preguntas como: ¿Para qué sirven las almohadas? ¿Y qué quieren poner sobre la almohada? ¿Y ahora qué hacemos con estas almohadas?

Mi discurso se acompaña de un tono de voz inquisitivo, respetuoso no instructivo, busco las posibilidades de acción por parte de las personas participantes, pretendo respetar su curiosidad innata. Ante mis cuestionamientos surgen las siguientes afirmaciones:

Docente: ¿Para qué sirven las almohadas?

F: Tira la almohada hacia arriba (respuesta corporal).

Docente: Para tirarlas.

Niños y niñas: Tiran sus almohadas hacia arriba.

F: Yo sé, que pongamos la cabeza en la almohada.

Docente: Que pongamos la cabeza en la almohada dice $\boldsymbol{F}$. 
doi: http://dx.doi.org/10.15359/ree.19-1.8

URL: http://www.una.ac.cr/educare

CORREO: educare@una.cr

Varios estudiantes dan ideas de cómo utilizar la almohada.

MCH: La cabecita (ponerse la almohada en la cabeza).

T: Tirarla.

Ma: Brincar las almohadas.

Vy: ¡Sin zapatos!

Es claro cómo cada vez más y más percibo a los niños y niñas como sujetos activos. GurdiánFernández (2007) destaca que el cambio de rol de la persona adulta conlleva al desborde en imaginación pura. Para llegar a este punto es necesario una profundización en el diálogo, tanto colectivo como personal, surgimos como seres dialógicos que aprenden desde el respeto, desde la diferencia con las demás personas, asumiéndonos como el sistema de interacciones en el cual nos reconstruimos constantemente.

Las relaciones con el estudiantado deben estar mediadas en todo momento por la aceptación y el respeto, es un transitar del respeto del otro y la otra hacia mi propio respeto, el vivir esto juntos y juntas expande nuestra capacidad de acción y reflexión (Maturana, 2002). Las personas protagonistas se empoderan totalmente de la experiencia, de la mano con su imaginación y creatividad, construyen un camino de almohadas. Como docente motivo sus acciones, acompaño con mi entusiasmo y apruebo este despertar, es un emocionarnos. Una de las estudiantes representa con toda claridad este paso hacia el respeto de la autonomía:

MA. Trae una canasta con muñecos de peluche pequeños, los reparte a sus compañeros y compañeras, algunos los tiran hacia arriba, otros los toman e imitan sonidos al tiempo que gatean sobre las almohadas.

Esta perspectiva de la realidad mueve a la niña a identificarse con sus pares, les da un lugar en su acción, comprende y siente que al lado de los demás se reconoce a sí misma, es una apertura a este tipo de participación activa y autónoma. Son actores y actoras que se sienten seguros de manifestarse libremente, pero esto solo es posible cuando como docente escucho su singularidad, cuando escucho su cuerpo, cuando mi mirada no fragmentada se reviste de coherencia y mi discurso coincide con mi quehacer. De forma que estoy "respetuosamente presente en la experiencia formadora del educando" (Freire, 2006, p. 59).

Complementa este proceso la comunicación asertiva, porque la autonomía del educando es posible cuando el lenguaje tanto verbal como corporal fluye sin limitantes impuestos por la figura de la maestra. En este sentido, un aporte que visualizo desde la vivencia de la investigación es mi posicionamiento en relación con los sujetos actuantes, ya que desde el paradigma cualitativo, quien investiga puede asumir un rol de "observador u observadora participante", 
con la intención de entrar en la dinámica educativa y establecer una relación abierta con las personas participantes (Taylor y Bogdan, 2000).

No obstante, considero que más allá de asumir un rol, es una actitud-visión, soy una "docente-participante", de los procesos educativos, de la vida misma; axiológicamente siempre soy participante, observo; pero también soy parte de esta realidad compleja que, reitero, no puedo fragmentar. Ahora bien, como "docente-participante" les propongo un juego alternativo a los niños y niñas, ellos aceptan mi aporte y acceden con emoción; esto me habla de un respeto mutuo, de una vivencia basada en la escucha del ser.

Continuando con la narración de la experiencia pedagógica, aprovecho el recurso de la música, y bailamos, pero cada vez que disminuye el volumen de la melodía, debemos sentarnos sobre la almohada, porque eso significa que un zancudo nos picó. Luego de jugar unos instantes, hay dos niñas que tienen otra propuesta y son escuchadas por sus pares y mi persona. Sus nuevas reglas son validadas, ellas comentan:

MA: Niña, usted tenía que picar a un compañero.

Da: $Y$ si toca a alguien se sienta.

Se refieren a una modificación del juego propuesto por la docente-participante, ellas brillan desde su creatividad e ingenio, me incorporan al juego colectivo, me convierto en el zancudo y debo perseguirles para picarles. Este ejemplo demuestra cómo su rol realmente es dinámico, ejercen su voz, deciden realmente lo que desean, proponen y podemos aceptar o no sus propuestas. La unión de estos componentes desencadena una comunicación asertiva. Sumado a esto puedo esclarecer su rol como "sujetos actuantes", lo cual tiene coherencia ontológica, epistemológica y metodológica (Gurdián-Fernández, 2007).

Una mayor transparencia en las interacciones beneficia un sistema que constituimos entre todos y todas, que se mueve a nuestro son y que cambia conforme cuestionamos lo que hacemos. Además, es necesaria una percepción de la realidad más sensorial, nuestro cuerpo es una compleja red de relaciones, palabras, movimientos, ideas, emociones, que en multiplicidad con los demás ejerce la transformación de los universos cotidianos.

Por ello, en este punto retomo que la realidad de aula es un sistema; por ello, considero la evolución del proceso como un todo. Al respecto Maturana (2002) me recuerda que somos seres individuales, pero a la vez conformamos un sistema social, el cual es cómplice de una constante recurrencia en las interacciones.

Ahora bien, retomo el tercer momento de análisis, anudo los saberes anteriores donde el educador o la educadora debe hacer frente a una escucha totalizadora del párvulo, así como mostrar un profundo respeto a la autonomía del niño y la niña, con un tercer saber que exige 
doi: http://dx.doi.org/10.15359/ree.19-1.8

URL: http://www.una.ac.cr/educare

CORREO: educare@una.cr

"querer bien a los educandos" (Freire, 2006, p. 135). Inicio nuevamente un proceso recursivo, donde mi compromiso es una escucha total en relación con rl pensar de los párvulos, siguiendo por supuesto esta nueva búsqueda de la afectividad en el vivir cotidiano.

Pretendiendo un estilo coherente entre mi discurso y mi práctica, procedo a reflexionar las opiniones, las ideas, el movimiento, las emociones, que externen las personas actuantes al mirar su propio accionar a través de un video corto, donde son los principales protagonistas, tanto en la experiencia con papel, como en el juego con almohadas. Por lo tanto, desde un punto de vista heurístico es posible hacer partícipes a los niños y las niñas en la construcción de significados a partir de la vivencia.

Con este ejercicio de devolverse una y otra vez a la escenas antes vividas, pretendo compartir un rol activo con el estudiantado, donde puedan expresar lo que sienten, lo que sintieron, lo que les gusta, lo que no les gustó. Esto me permite en primer lugar una apertura al diálogo, en segundo lugar fortalecer nuestro vínculo desde el respeto por las ideas del otro, y en tercer lugar generar espacios para la validación de los sentimientos.

La escena inicia cuando les comento que observaremos una película, se muestran muy emocionados y emocionadas, durante los primeros segundos escucho un gran silencio, su concentración es total, sus miradas, sonrisas, movimientos están en una misma sintonía; confirmo que observarnos en nuestro actuar nos confronta con una serie de emociones que nos posiciona en un antes y en un después, espacio-tiempo que se desdobla y deja hablar por sí misma a la vivencia (Assmann, 2002).

Entonces, desde el punto de vista dialéctico, inicia un intercambio entre las personas actoras, una reconstrucción de la historia, desde el interior de nuestra dinámica de aula, sus voces hablan por sí solas, no hay una barrera entre lo que yo pienso y lo que ellos y ellas desean comunicar, todo fluye. Algunas de sus expresiones al mirarse en el video son:

F: Yo estaba como por allá (señala con su dedo).

MA: Yyo por allá.

D: Ahí estoy yo.

JD: Ahí estoy yo.

An: Ahí estoy yo.

Ese "ahí estoy yo" es crucial, me habla de su presencia, de su valiosa participación, y de una validación del yo ante los otros. Les llamo actores, pues el rol que han logrado asumir es totalmente dinámico y comprometido con la investigación acción, definitivamente son sujetos actuantes (Gurdián-Fernández, 2007). 
Para estos niños y niñas el mirarse en el video es un ejercicio que les abre las puertas para posicionarse de la vivencia en otro tiempo; al respecto, Freire (2005) esboza que "al destemporalizarse inicia su integración en el tiempo" (106). Es un reflejo de su ser en otro espacio, el poder externar sus emociones les enriquece, valida su singularidad; pero además, evidenció un valor agregado, cuando dan también un lugar a sus pares, esto se presenta cuando mencionan "ahí está ..." ese otro que complementa mi existencia y que nos interconecta con todo lo demás.

La movilidad física de las personas participantes está acompañada por su movilidad lingüística y esto no significa más que la construcción de ambientes pedagógicos desde la libertad del ser y del sentir. Los individuos espectadores van recordando algunos elementos que sucedieron conforme transcurre la película. Por ejemplo:

Como una piscina (cuando cada estudiante utilizó la montaña de papel como una piscina).

La niña, ¿por qué se tiró? (cuando los párvulos invitaron a la docente a tirarse igualmente que ellos y ellas en la piscina de papel).

La peluca (cuando una niña colocó una gran cantidad de papel sobre su cabeza).

Todo lo anterior simboliza una gran responsabilidad, ya que los párvulos no se amoldaron a mis deseos o a mis directrices, fueron desafiados en el sentido de ser partícipes de su propia formación (Freire, 2006). El retomar este video días después, tiene en las personas participantes un impacto poderoso en su ser, porque reafirman su posición protagonista de los hechos, no son un objeto, son sujetos en acción.

Como docente comprendo mejor sus vínculos, respeto su construcción de conocimiento, su forma de comunicarse y expresarse (Gurdián-Fernández, 2007). Esta recuperación del pasado a partir del video y el contraste con la realidad desde el pensar y sentir de los protagonistas permite trascender hacia otros campos de entendimiento; donde la imagen puede tomar el lugar de la palabra y expresar o reconstruir la vivencia (Taylor y Bogdan, 2000). Las sensaciones y emociones que a los 3 y 4 años de edad es difícil poner en palabras, regresan y toman sentido cuando el video revela eso que no pudimos decir o percibimos cuando lo vivimos.

De manera que las visiones se entrecruzan, niños y niñas dan un paso más hacia la pedagogía de la autonomía, donde la libertad es asumida por la palabra y por la acción. Yo como docente dejo a un lado la toma de decisiones arbitrarias, me emociona ver la dinámica de aula desde otro punto de vista, que me permite fortalecer un vínculo crítico que favorece nuestra convivencia, nuestra cohesión como grupo.

Este panorama debe ser visualizado desde la posibilidad que se está ofreciendo al párvulo de validar su palabra, sus sentimientos, sus preferencias e incluso la toma de decisiones. Según Freire (2005): "no puede haber palabra verdadera que no sea un conjunto solidario de dos 
doi: http://dx.doi.org/10.15359/ree.19-1.8

URL: http://www.una.ac.cr/educare

CORREO: educare@una.cr

dimensiones indicotomizables, reflexión y acción" (p. 16). Confirmo que es posible una mirada crítica de las acciones realizadas días atrás y la forma en que se moviliza el pensamiento es a través de este tipo de estrategias que permiten expresar la verdadera palabra, esta que viene de adentro, que no ha sido manipulada por mi persona, la cual surge en la espontaneidad y que, como mencioné antes, es además una expresión de todo el cuerpo.

Por consiguiente, el espacio y el derecho que estas personas actoras tienen para decir su palabra es un paso para transformar su realidad: la tarea de educar realmente se humaniza (Freire, 2005). Este devolverme en el tiempo con los niños y las niñas es una propuesta que realmente trasciende a un nivel más dialógico; no basta mi crítica, es necesaria su posición, su voz, lo que tengan que decir.

La construcción de nuevos espacios pedagógicos llena de vida la dinámica de aula y permite, a su vez, "extraer, exaltar y recrear el potencial vital y de crecimiento que contiene cualquier suceso, cualquier incidencia, cualquier realidad humana" (Toro, 2006, p. 25). Por lo tanto, como todo debe fluir y mejorar, el reto está en continuar con los procesos de apertura donde estudiantes tengan un real protagonismo en la toma de decisiones, para seguir reconstruyendo una "educación valiente" que permita, como sustenta Freire (2005), alcanzar de forma coherente una práctica de la libertad.

\section{Reflexiones: Una sinfonía que transforma}

Inicié una búsqueda personal, tratando en un primer momento de mirar mi práctica docente y dar un sentido diferente a lo que estaba haciendo cotidianamente, esto de la mano con la investigación-acción; en este caminar mi pensamiento se vio envuelto con los movimientos propios de la complejidad, crear y recrear los escenarios pedagógicos (Morín, 1998, citado por Gurdián-Fernández, 2007). Esta recursividad de los procesos educativos han sido pequeñas dosis de transformación, donde el reto fundamental fue autotrascenderme.

Pude cuestionar mi ser y quehacer docente (Latorre, 2003), proceso de reflexión acción que favoreció autoorganizar mis propias creencias, temores, dilemas, sentimientos, conocimientos y pensamientos. Experiencia que se convirtió en una invitación a mirar con detenimiento las múltiples realidades que se gestan a diario en la dinámica de aula y aprender a aprender de estas.

Esta transformación impactó directamente en mi forma de percibir el rol del niño y la niña en el aula preescolar, cuando les permití asumir un verdadero protagonismo, al hacerlo, fueron transformados y transformadores. Nuestras historias se entrecruzaron y a partir de la convivencia nos aventuramos en la búsqueda permanente de una educación más abierta al cambio, humanizante, defensora de la autonomía, libre. Cuando los espacios de aula se abrieron a esta dimensión de intercambios simples, conscientes, tendientes a la autoorganización, el estudiantado fue actuante dinámico que ejerció su derecho de tomar decisiones.

Cuando apostamos por una dinámica dialéctica, inevitablemente los viejos paradigmas educativos son renovados; mi papel de maestra "docente-protagonista" fue transformado al 
tiempo que asumí una escucha totalizadora; empecé a derribar concepciones, creencias, ideas, prácticas que no eran coherentes con mi discurso. Y menciono que no eran coherentes con mi discurso, porque en lugar de provocar y liberar procesos educativos estaba controlando los escenarios e imponiendo mi forma de pensar, no estaba dejando ser a los niños y las niñas.

De manera que la fuerza vital de los niños y las niñas, sus gestos, su mirada, su cuerpo, su decir, su pensar, su actuar ejerció el poder de la metamorfosis. De ahora en adelante nos renovaremos cada vez que interactuemos, educandos ejercen su autonomía, toman decisiones, se asumen en su desarrollo, validan su presente, actúan en el mundo y con el mundo que les rodea (Freire, 2006). Están en un lugar que les permite empoderarse de aquello que solo ellos y ellas pueden alcanzar: su libertad.

Este ir y venir en los procesos nos invitó a reflexionar lo que vivimos en la dinámica de aula, accediendo a una posición crítica de nuestras realidades. En conjunto, construimos las diversas experiencias, nos nutrimos del otro en una bella convivencia.

Además, la comunicación asertiva jugó un papel vital, ya que nuestras prácticas se tiñeron de miradas encarnadas en el respeto, voces que ya no estarán en silencio, una escucha respetuosa del otro y la otra, espacios llenos de libertad, se vivió una emancipación de la expresividad. Lo anterior fortaleció el vínculo que como grupo hemos ido alcanzando, a través de una convivencia afectiva, armoniosa, flexible y dinámica, la cual nos da las herramientas para sentirnos seguros, confiados, amados; este proceso investigativo ha tejido y fortalecido relaciones interpersonales positivas para la dinámica en este nivel de preescolar. No es más que la traducción del protagonismo de los párvulos, la alegría de trasformar nuestra realidad en lo que realmente deseamos.

Esta realidad es un sistema cambiante; pero que nos vincula como seres aprendientes, nos modifica a partir de nuestras interacciones. Es así como logro reconocer los campos morfogénicos que, según Sheldrake (1994), son "regiones invisibles de influencia con propiedades intrínsecamente holísticas" (p. 120). Efectivamente, a nivel social vivimos una serie de fuerzas continuadas que nos permitieron relacionarnos con los otros, aprender de estas interacciones y mantener el equilibrio, reconstruyendo las prácticas y los discursos, desde la reflexión-acción. La recursividad de los procesos a través del video fue un ejercicio que liberó nuestra presencia, nos permitió percibir los escenarios con otra mirada, abrieron nuestro pensamiento de una forma más relacional. Se dio un movimiento dialéctico de los tiempos, el pasado transforma el presente y este se modifica por la presencia del pasado (Assmann, 2002).

Metodológicamente, fue posible hacer investigación-acción con niños y niñas de 3 y 4 años de edad, porque no hay duda que son personas activas; fue posible compartir un rol reflexivo: miraron, yo miré, escucharon, yo escuché, hablaron, yo hablé, por lo tanto, "quien enseña aprende al enseñar y quien aprende enseña al aprender" (Freire, 2006, p. 25). 
REVISTA ELECTRÓNICA EdUCARE (EDUCARE ELECTRONIC JOURNAL) EISSN: 1409-4258 VOL. 19(1) ENERO-ABRIL, 2015: 131-146

doi: http://dx.doi.org/10.15359/ree.19-1.8

URL: http://www.una.ac.cr/educare

CORREO: educare@una.cr

Una última reflexión, sello mi compromiso con los niños y niñas en el quehacer cotidiano, cuando les permito ser, es una práctica humana, somos personas más personas

(Freire, 2006)

La búsqueda no acaba, es un despertar a una conciencia crítica, a una convivencia auténtica, a una aventura sin fin...

(Víquez, 2013)

\section{Referencias}

Assmann, H. (2002). Placer y ternura en la educación. Hacia una sociedad aprendiente. Madrid: Narcea.

Freire, P. (2005). La educación como práctica de libertad. Buenos Aires: Siglo XXI.

Freire, P. (2006). Pedagogía de la autonomía. Saberes necesarios para la práctica educativa (11 ed.). México: Siglo XXI.

Gurdián-Fernández, A. (2007). El paradigma cualitativo en la investigación socio-educativa. San José, Costa Rica: Coordinación Educativa y Cultural Centroamericana y Agencia Española de Cooperación Internacional.

Latorre, A. (2003). La investigación acción: Conocer y cambiar la práctica educativa. Barcelona: Graó.

Maturana, H. (2002). Transformación en la convivencia ( $2^{\text {a }}$ ed.). Santiago: Dolmen Ediciones.

McKernan, J. (1999). Investigación-acción y curriculum. Madrid: Morata.

Sheldrake, R. (1994). El renacimiento de la naturaleza. La nueva imagen de la ciencia y de Dios. Barcelona: Ediciones Paidós Ibérica.

Taylor, S. y Bogdan, R. (2000). Introducción a los métodos cualitativos de investigación. La búsqueda de significados ( $3^{\mathrm{a}}$ ed.). Barcelona: Ediciones Paidós Ibérica.

Toro, J. (2006). Educar con "co-razón" (2a ed.). Bilbao: Editorial Desclée de Brouwer.

Víquez, E. (2013). Frase inédita.

\section{Cómo citar este artículo en APA:}

Víquez-Zavala, E. (enero-abril, 2015). El lugar del niño y la niña en la toma de decisiones en la dinámica de aula: Reflexiones desde la pedagogía de la autonomía de Paulo Freire. Revista Electrónica Educare, 19(1), 131146. doi: http://dx.doi.org/10.15359/ree.19-1.8

Nota: Para citar este artículo en otros sistemas puede consultar el hipervínculo "Como citar el artículo" en la barra derecha de nuestro sitio web: http://www.revistas.una.ac.cr/index.php/EDUCARE/index 